\title{
Stereoselective Recognition of Amethopterin Enantiomers by the Rat Proton-Coupled Folate Transporter
}

\author{
Tomoya Narawa,* Toshiaki Yano, and Tomoo Itoh \\ School of Pharmacy, Kitasato University; 5-9-1 Shirokane, Minato-ku, Tokyo 108-8641, Japan. \\ Received September 25, 2014; accepted January 12, 2015
}

The stereoselective transport of methotrexate (L-amethopterin, L-MTX) and its enantiomer (D-amethopterin, D-MTX) by the rat proton-coupled folate transporter (rPCFT) were examined using rPCFT-expressing HEK293 cells. The initial rate of uptake of $\left[{ }^{3} \mathrm{H}\right]-\mathrm{L}-\mathrm{MTX}$ by the rPCFT followed Michaelis-Menten kinetics, with a $K_{\mathrm{m}}$ value of $2.1 \mu \mathrm{M}$. Dixon plots revealed that the uptake of L-MTX by the rPCFT was inhibited in a competitive manner by unlabeled L-MTX and D-MTX, with $K_{\mathrm{i}}$ values of approximately 1.3 and $150 \mu \mathrm{M}$, respectively. The initial rate of uptake of D-MTX by the rPCFT also followed Michaelis-Menten kinetics, with a $K_{\mathrm{m}}$ value of $190 \mu \mathrm{M}$. The results of the current study demonstrate that the different enantiomers of MTX are transported in a highly stereoselective manner by the rPCFT, with the uptake clearance of L-MTX being approximately 46-fold greater than that of D-MTX. The observed stereoselectivity of the rPCFT was found to be comparable with that of the human PCFT.

Key words methotrexate; amethopterin; enantiomer; species difference; stereoselective transport; protoncoupled folate transporter

Folates are essential nutrients for cell growth in various mammalian cells and are transported across cell membranes by the reduced folate carrier (RFC, SLC19A1) or the protoncoupled folate transporter (PCFT, SLC46A1). ${ }^{1-4)}$ The cDNA of the RFC has been cloned in several different species, including mice, hamsters, and humans, and its transport characteristics have been fully elucidated. ${ }^{5-11)}$ The RFC can only transport reduced folates, with maximal folate transport being observed at neutral $\mathrm{pH}^{2,4,12)}$ Although the PCFT was originally identified as a heme carrier protein, subsequent research revealed that folates are good substrates of the PCFT. ${ }^{3)}$ The PCFT is expressed in the epithelial cells of the small intestine and involved in the absorption of both reduced and oxidized folates, with a $\mathrm{H}^{+}$gradient providing the driving force for both of these adsorption processes. ${ }^{12)}$ Given that the microclimate $\mathrm{pH}$ at the surface of epithelial cells is acidic, the PCFT could also play a major role in the intestinal absorption of folates.

Hereditary folate malabsorption (HFM) is a rare autosomal recessive disorder in humans. This disease is characterized by symptoms similar to those associated with folate deficiency and generally appears within 3-6 months of birth. Infants with HFM develop anemia, diarrhea, immune deficiency, peripheral neuropathies, and seizures. ${ }^{13)}$ Several studies on patients with HFM have revealed a loss of PCFT function due to mutations in the gene encoding the PCFT. ${ }^{14,15)}$ Loss of PCFT function leads to decreased intestinal absorption of folate and reduced folate transport into the central nervous system. ${ }^{14)}$ These findings demonstrate the importance of the role played by the PCFT in intestinal absorption and the distribution of folates to the brain.

Methotrexate (L-amethopterin, L-MTX) is used clinically as an antineoplastic and antirheumatic drug. The molecular structure of L-MTX is similar to that of folic acid (FA), meaning that L-MTX is rapidly absorbed in the small intestine by the PCFT following its oral administration. D-Amethopterin (D-MTX) is the optical isomer of L-MTX, and the absorption of D-MTX from the human small intestine occurs at a significantly slower rate than that of L-MTX. It was reported that the area under the plasma concentration-time curve (AUC) following the oral administration of L-MTX is approximately 40 -fold greater than that of a dose of D-MTX. ${ }^{16}$ )

Our previous studies revealed that the human PCFT (hPCFT)-mediated transport of the different enantiomers of MTX occurred in a stereoselective manner. ${ }^{17)}$ That particular study used hPCFT-expressing human embryonic kidney (HEK) 293 cells to show that both L- and D-MTX were substrates of the hPCFT and that the $K_{\mathrm{m}}$ value of L-MTX $(4.98 \mu \mathrm{M})$ was significantly lower than that of D-MTX $(211 \mu \mathrm{M})$. The results of that study also revealed that the observed stereoselective transport of MTX occurred as a consequence of significant differences in the affinity of the hPCFT for the various enantiomers of MTX.

The stereoselectivity of the human RFC (hRFC) and rat RFC (rRFC) were investigated in our laboratory. Both L- and D-MTX competitively inhibited the RFC-mediated uptake of $\left[{ }^{3} \mathrm{H}\right]$-L-MTX in hRFC-expressing HEK293 cells. The $K_{\mathrm{i}}$ value of D-MTX was approximately 10 -fold greater than that of L-MTX, and the hRFC-mediated uptake clearance of L-MTX was $15-30$-fold greater than that of D-MTX. ${ }^{18)}$ On the other hand, according to our preliminary results, unlabeled L- and D-MTX both inhibited the uptake of $\left[{ }^{3} \mathrm{H}\right]-\mathrm{L}-\mathrm{MTX}$ in a competitive manner with very similar $K_{\mathrm{i}}$ values. Moreover, no differences were observed in the rRFC-mediated uptake clearance between L- and D-MTX. These results demonstrated that there are significant species differences in the stereoselective transport of MTX enantiomers between humans and rats.

Since species differences were observed in the stereoselective transport of MTX via the RFC, the present study aimed to investigate whether there are species differences in the stereoselective transport of the PCFT. Since we established a HEK293 cell line capable of stably expressing the rPCFT, we used this cell line to investigate the stereoselectivity of rPCFT toward the transport of the different enantiomers of MTX. 


\section{MATERIALS AND METHODS}

Materials L-MTX and 2-[4-(2-hydroxyethyl)-1-piperazinyl]ethanesulfonic acid (HEPES) were purchased from Nacalai Tesque (Kyoto, Japan). D-MTX was purchased from Kanto Kagaku Co. (Tokyo, Japan). 2-Morpholinoethanesulfonic acid monohydrate (MES) was purchased from Wako Pure Chemical Industries, Ltd. (Osaka, Japan). $\left[{ }^{3} \mathrm{H}\right]-\mathrm{L}-\mathrm{MTX}$ (specific activity, $31 \mathrm{Ci} / \mathrm{mmol}$ ) was purchased from Moravek Biochemicals, Inc. (Brea, CA, U.S.A.) and used without further purification. All other chemicals used in the study were purchased as the highest available grade.

Construction of Stably Transfected HEK293 Cells Expressing the rPCFT Male Sprague-Dawley (SD) rats were purchased from Japan SLC (Hamamatsu, Japan). Animal experiments were approved by the Kitasato University Institutional Animal Care and Use Committee and were performed in accordance with the Regulations for the Care and Use of Laboratory Animals in Kitasato University. Total RNA from the small intestinal mucosa of male SD rats was isolated using Sepasol RNA I super according to the manufacturer's (Nacalai Tesque) protocol. The concentration of RNA was determined by absorbance at $260 / 280 \mathrm{~nm}$. A small portion $(1 \mu \mathrm{g})$ of the total RNA was heat denatured with $1 \mu \mathrm{L}$ of random primer at $70^{\circ} \mathrm{C}$ for $5 \mathrm{~min}$, placed on ice for $1 \mathrm{~min}$, and then mixed with $5 \mu \mathrm{L}$ of Moloney murine leukemia virus (M-MLV) Reverse Transcriptase $5 \times$ Reaction Buffer, $1.5 \mu \mathrm{L}$ of $10 \mathrm{~mm}$ deoxyribonucleotide triphosphate (dNTP) mixture, and $0.2 \mu \mathrm{L}$ of M-MLV reverse transcriptase (Promega, Madison, WI, U.S.A.). The mixture was then incubated at $37^{\circ} \mathrm{C}$ for $60 \mathrm{~min}$, followed by incubation at $70^{\circ} \mathrm{C}$ for $15 \mathrm{~min}$. The following oligonucleotide primers were used in the experiments: rPCFT/EcoRI 5'-GAATTCGCGCATGGA GGGGCGCGTGA-3' (forward primer) and rPCFT/XbaI 5'-GCTCTAGATGG CTT CTGGCA GCT CAGGA-3' (reverse primer). The reaction mixture $(50 \mu \mathrm{L})$ contained $1 \mu \mathrm{L}$ of reverse transcription product as the template DNA, $10 \mathrm{pmol}$ of the forward and reverse primers, $10 \mathrm{nmol}$ of the dNTP mixture, 10× High Fidelity PCR Buffer, and 1 unit of Platinum Taq DNA Polymerase High Fidelity. After an initial period of denaturation at $90^{\circ} \mathrm{C}$ for $2 \mathrm{~min}$, the targeted nucleotides were amplified for 40 cycles, with denaturation at $94^{\circ} \mathrm{C}$ for $30 \mathrm{~s}$, annealing at $55^{\circ} \mathrm{C}$ for $30 \mathrm{~s}$, extension at $72^{\circ} \mathrm{C}$ for $2 \mathrm{~min}$, and a final extension stage at $72^{\circ} \mathrm{C}$ for $10 \mathrm{~min}$. The amplified cDNA product was subcloned into a pGEM-T Easy vector (Promega) and transferred into a mammalian expression vector, pcDNA3.1(+) (Invitrogen Co., Grand Island, NY, U.S.A.).

rPCFT-expressing HEK293 cells and control cells (Mock) were constructed by transfecting the HEK293 cells with the expression vector described above or a control pcDNA3.1 vector, respectively, using FuGENE6 (Roche Diagnostics, Indianapolis, IN, U.S.A.) according to the manufacturer's instructions. The tranformants were selected using $600 \mu \mathrm{g} / \mathrm{mL}$ of antibiotic G418 sulfate (Nacalai Tesque) over a 2-week period. An uptake study was conducted using several clones, and the clone with the highest uptake activity was selected for use in the following experiments.

Cell Culture HEK293 cells were obtained from the Cell Resource Center for Biomedical Research, Tohoku University (Sendai, Japan). The cells were maintained at $37^{\circ} \mathrm{C}$ in a humidified atmosphere containing $5 \% \mathrm{CO}_{2}$ in a culture medium consisting of Dulbecco's modified Eagle's medium (DMEM), $100 \mathrm{U} / \mathrm{mL}$ of penicillin, $100 \mu \mathrm{g} / \mathrm{mL}$ of streptomycin, and $10 \%$ fetal bovine serum.

rPCFT-HEK293 cells and HEK293-Mock cells were grown in DMEM containing $100 \mathrm{U} / \mathrm{mL}$ of penicillin, $100 \mu \mathrm{g} / \mathrm{mL}$ of streptomycin, $600 \mu \mathrm{g} / \mathrm{mL}$ of antibiotic G418 sulfate, and $10 \%$ fetal bovine serum. The cells were seeded in multiple-well plates coated with poly-D-lysine at a density of $1.0 \times 10^{5}$ cells/ well.

Uptake Study Hank's balanced salt solution (HBSS: $145 \mathrm{~mm} \mathrm{NaCl}, 3 \mathrm{~mm} \mathrm{KCl}, 1 \mathrm{~mm} \mathrm{CaCl} 2,0.5 \mathrm{~mm} \mathrm{MgCl}_{2}$ ) containing $5 \mathrm{~mm}$ D-glucose and $5 \mathrm{mM} \operatorname{MES}(\mathrm{pH} 6.0)$ was used as the uptake medium. HBSS containing $5 \mathrm{~mm}$ D-glucose and $5 \mathrm{~mm}$ HEPES ( $\mathrm{pH}$ 7.4) was used as the rinse medium.

The rPCFT-HEK293 cells and HEK293-Mock cells used in the uptake study were placed in multiple-well plates and rinsed twice before being preincubated with the rinse medium ( $\mathrm{pH} 7.4$ ) for $10 \mathrm{~min}$ at $37^{\circ} \mathrm{C}$. Uptake was initiated by adding $0.5 \mathrm{~mL}$ of the preincubated drug solution. Uptake medium $(\mathrm{pH}$ 6.0) containing $\left[{ }^{3} \mathrm{H}\right]$-L-MTX, unlabeled L-MTX, or D-MTX was used as the drug solution. The drug solution was aspirated for the appropriate length of time necessary to terminate the uptake. The cells were rinsed twice with ice-cold rinse medium ( $\mathrm{pH} 7.4$ ) and then lysed with $1 \mathrm{~mL}$ of $0.1 \%$ Triton $\mathrm{X}-100$. To determine the uptake amount of $\left[{ }^{3} \mathrm{H}\right]-\mathrm{L}-\mathrm{MTX}$, a 0.8 $\mathrm{mL}$ aliquot of the cell lysate was transferred to a scintillation vial, where it was treated with $5 \mathrm{~mL}$ of Clear-sol I (Nacalai Tesque). The radioactivity of the resulting solution was measured by liquid scintillation counting. To determine the uptake amount of D-MTX, a $0.8-\mathrm{mL}$ aliquot of the cell lysate was treated with $0.8 \mathrm{~mL}$ of acetonitrile, and the resulting mixture was vortexed. The vortexed mixture was then centrifuged at $825 \times \boldsymbol{g}$ for $15 \mathrm{~min}$, and the supernatant was filtered using a Cosmonice filter $\mathrm{S}(0.45 \mu \mathrm{m}$; Nacalai Tesque). The filtrate was dried under a gentle stream of nitrogen gas at $80^{\circ} \mathrm{C}$ to give a residue, which was dissolved in $100 \mu \mathrm{L}$ of the mobile phase. A $30-\mu \mathrm{L}$ aliquot was injected into the LC-MS/MS system, which was operated under a previously published set of conditions. ${ }^{17)}$

For the inhibition study, each inhibitor was added to the drug solution at an appropriate concentration, and the uptake of the drug was measured in the same manner as that described above. The drugs and inhibitors were dissolved in dimethyl sulfoxide (DMSO) and the final concentration of DMSO in the drug solution was $1 \%$ or less in each case.

Protein Assay For protein determination, the rPCFTHEK293 and HEK293-Mock cells were dissolved in $1 \mathrm{~mL}$ of $0.1 \%$ Triton $\mathrm{X}-100$, and the protein concentrations were determined using a Bio-Rad protein assay kit (Bio-Rad Laboratories, Richmond, CA, U.S.A.) with bovine serum albumin as a standard.

Data Analysis The kinetic parameters for the uptake of L-MTX and D-MTX uptake were calculated, and the resulting data were fitted to the following equation using a nonlinear least-squares method $^{19)}$ :

$$
v=\frac{V_{\max } \cdot[S]}{K_{\mathrm{m}}+[S]}
$$

where $v$ is the carrier-mediated initial uptake rate, $V_{\max }$ is the maximum uptake rate, $K_{\mathrm{m}}$ is the Michaelis constant, and [S] is the initial concentration of the drug. 


\section{RESULTS}

Uptake of L-MTX Figure 1 shows the time courses for the uptake of $0.02 \mu \mathrm{M}$ of $\left[{ }^{3} \mathrm{H}\right]-\mathrm{L}-\mathrm{MTX}$ into the rPCFT-HEK293 and Mock cells. The uptake into the rPCFT-HEK293 cells was significantly higher than that into the Mock cells. Based on the results in Fig. 1, the initial rate of uptake was calculated from the uptake amount at $1 \mathrm{~min}$, which was determined according to the following analyses.

The initial uptake rate of $\left[{ }^{3} \mathrm{H}\right]-\mathrm{L}-\mathrm{MTX}$ was measured at variety of different concentrations $(0.5-40 \mu \mathrm{M})$ in the presence of a $\mathrm{H}^{+}$gradient $(\mathrm{pH}$ 6.0). The amount of rPCFT-mediated uptake was calculated by subtracting the uptake into Mock cells from that into rPCFT-HEK293 cells. The results of this analysis are shown in Figs. 2A and B. Single-component analysis gave $K_{\mathrm{m}}=2.14 \pm 0.22 \mu \mathrm{M}$ and $V_{\max }=260 \pm 12 \mathrm{pmol} / \mathrm{min} /$

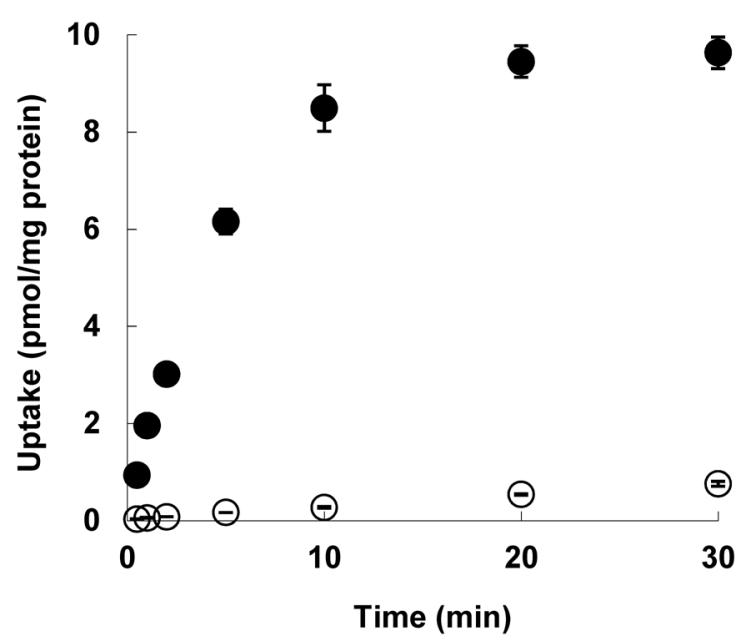

Fig. 1. Time Course of the Uptake of $0.02 \mu \mathrm{M}$ of L-MTX at an Extracellular $\mathrm{pH}$ of 6.0

Each point represents the mean \pm S.D. of three determinations. $\bullet$ rPCFT-transfected HEK293 cells; O, vector-transfected HEK293 cells (Mock) mg protein [mean \pm standard deviation (S.D.), $n=3$ ] with an Akaike's Information Criterion (AIC) value of -21.3 . The following uptake parameters were obtained when the data were analyzed with two components: $K_{\mathrm{m}, 1}=1.22 \pm 0.84 \mu \mathrm{M}$; $V_{\max , 1}=159 \pm 118 \mathrm{pmol} / \mathrm{min} / \mathrm{mg}$ protein; $K_{\mathrm{m}, 2}=11.5 \pm 21.0 \mu \mathrm{M}$; and $V_{\max , 2}=145 \pm 86 \mathrm{pmol} / \mathrm{min} / \mathrm{mg}$ protein (mean \pm S.D., $n=3$ ). The AIC value for two-component analysis was -24.1 .

Inhibition Studies The initial uptake rates of $0.4,0.8$, and $2 \mu \mathrm{M}$ of $\left[{ }^{3} \mathrm{H}\right]$-L-MTX were measured in the presence of 0 , 1 , and $2 \mu \mathrm{M}$ of unlabeled L-MTX, and the resulting data were analyzed using a Dixon plot (Fig. 3A). Unlabeled L-MTX competitively inhibited $\left[{ }^{3} \mathrm{H}\right]-\mathrm{L}-\mathrm{MTX}$ uptake, with a $K_{\mathrm{i}}$ value of $1.25 \mu \mathrm{M}$. The initial uptake rates of $0.4,0.8$, and $2 \mu \mathrm{M}$ of $\left[{ }^{3} \mathrm{H}\right]-$ L-MTX were also measured in the presence of 0,150 , and $300 \mu \mathrm{M}$ of D-MTX. A Dixon plot of the resulting data showed that D-MTX inhibited the uptake of $\left[{ }^{3} \mathrm{H}\right]-\mathrm{L}-\mathrm{MTX}$ in a competitive manner, with a $K_{\mathrm{i}}$ value of $149 \mu \mathrm{M}$ (Fig. 3B).

Uptake of D-MTX Figure 4 shows the time courses for the uptake of $20 \mu \mathrm{M}$ of D-MTX into the rPCFT-HEK293 and Mock cells. The uptake of D-MTX into rPCFT-HEK293 cells was significantly higher than that into Mock cells. Based on the results shown in Fig. 4, the initial uptake rate was calculated from the uptake amount at $2 \mathrm{~min}$ according to the following analyses.

The initial rate of uptake of D-MTX was measured at a variety of different concentrations $(20-600 \mu \mathrm{M})$ in the presence of a $\mathrm{H}^{+}$gradient ( $\mathrm{pH}$ 6.0). The rPCFT-mediated uptake was calculated by subtracting the uptake into Mock cells from that into rPCFT-HEK293 cells, and the results are shown in Fig. 5A. An Eadie-Hofstee plot of the rPCFT-mediated uptake indicated that the saturable uptake of D-MTX was mediated by a single transport system (Fig. 5B). The AIC value of one-component analysis was determined to be -9.91 , whereas the value obtained from the two-component analysis was -5.97 . The uptake parameters were calculated using Eq. 1, which gave the following values: $K_{\mathrm{m}}=192 \pm 55 \mu \mathrm{M}$; and $V_{\max }=509 \pm 88 \mathrm{pmol} / \mathrm{min} / \mathrm{mg}$ protein (mean \pm S.D., $n=3$ ).
A

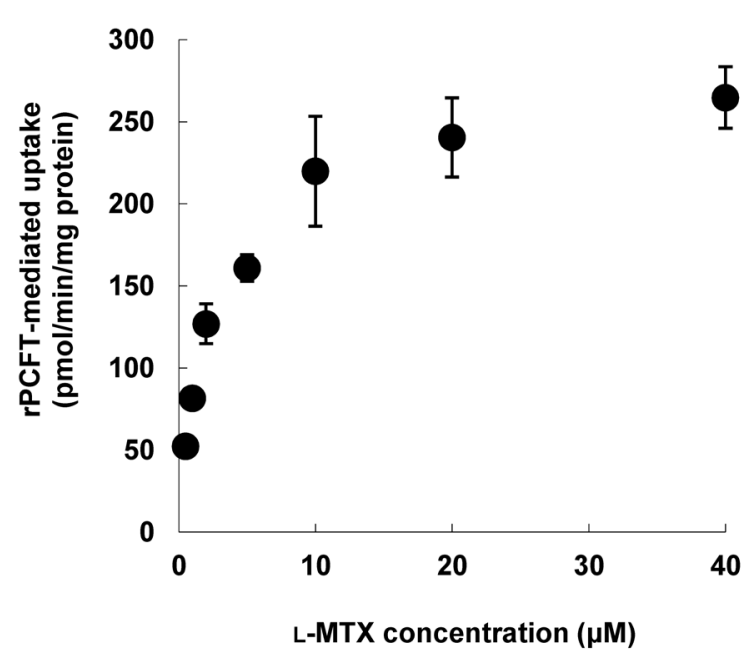

B

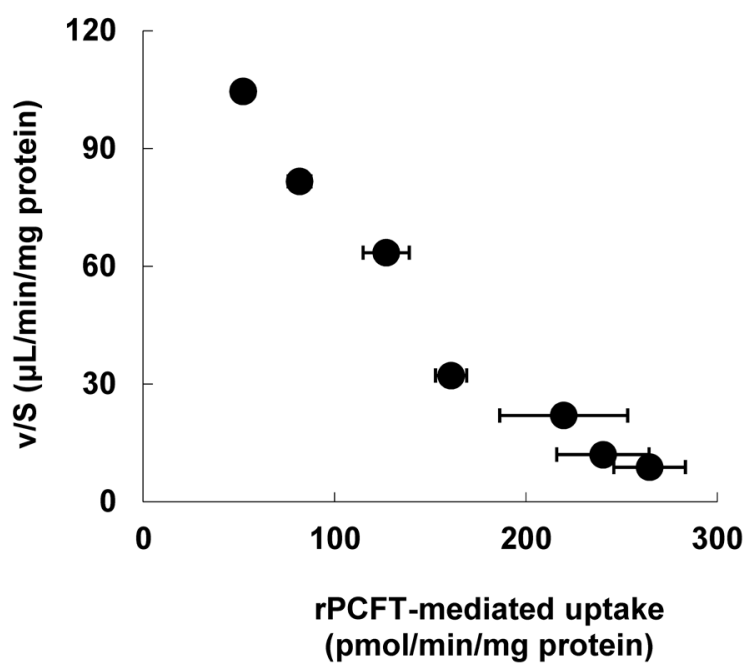

Fig. 2. Concentration Dependence of the Initial Rate of Uptake of rPCFT-Mediated L-MTX Uptake (A) Eadie-Hofstee Plot of the rPCFT-Mediated Uptake of L-MTX (B)

Each point represents the mean \pm S.D. of three determinations. The rPCFT-mediated uptake was calculated by subtracting the uptake into Mock cells from that into rPCFT-HEK293 cells. 
A

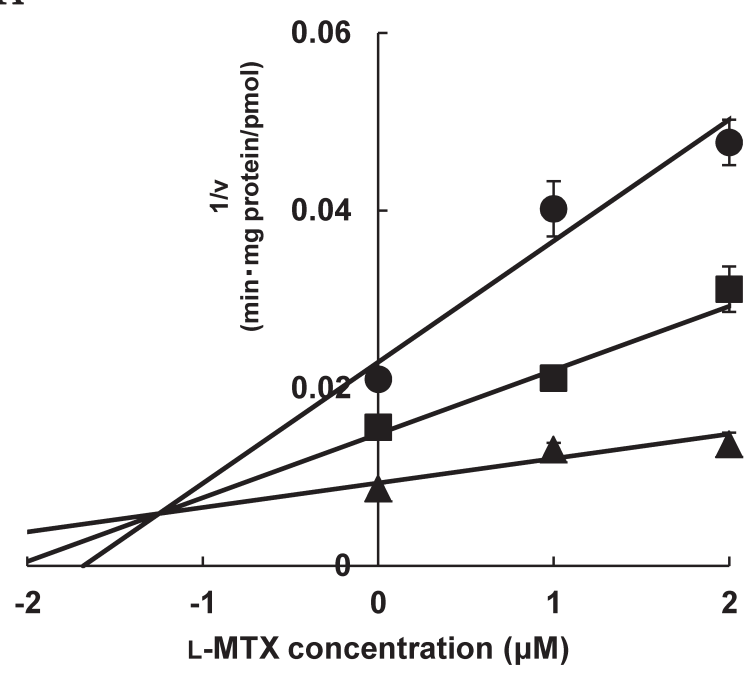

B

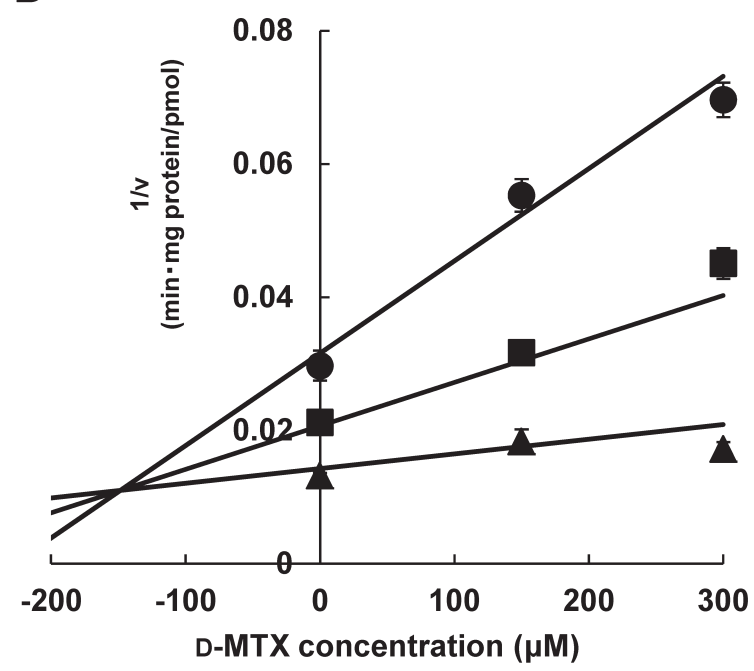

Fig. 3. Dixon Plots of the Inhibitory Effects of Unlabeled L-MTX and D-MTX on the rPCFT-Mediated Uptake of [ $\left.{ }^{3} \mathrm{H}\right]-\mathrm{L}-\mathrm{MTX}$

The uptake values were measured at $0.4(\bullet), 0.8(\boldsymbol{\square})$, and $2.0(\mathbf{\Delta}) \mu \mathrm{M}$ in the presence of 0,1 , and $2 \mu \mathrm{M}$ of L-MTX (A); and 0,150 , and $300 \mu \mathrm{M}$ of D-MTX (B). Each point represents the mean \pm S.D. of three determinations.

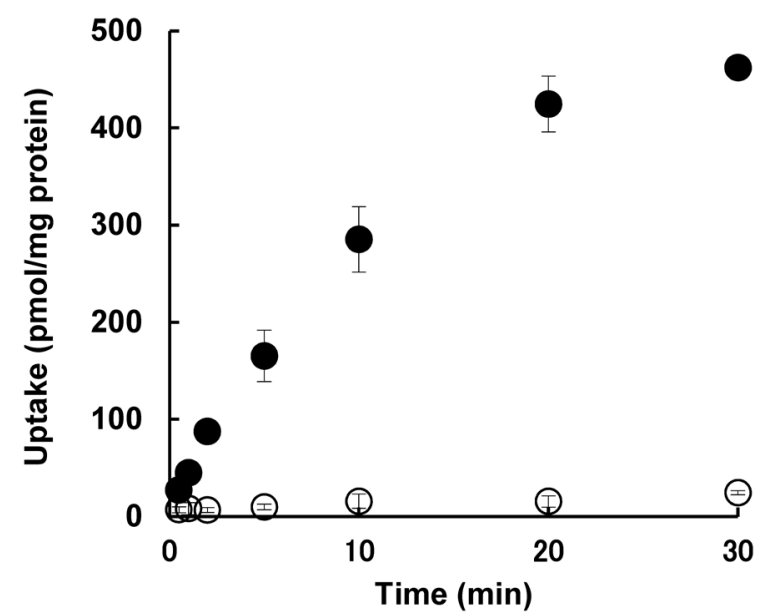

Fig. 4. Time Course of the Uptake of $20 \mu \mathrm{M}$ of D-MTX at an Extracellular $\mathrm{pH}$ of 6.0

Each point represents the mean \pm S.D. of three determinations. transfected HEK293 cells; O, vector-transfected HEK293 cells (Mock).

Comparison of L- and D-MTX Uptake The rates of uptake of $0.2 \mu \mathrm{M}$ of $\left[{ }^{3} \mathrm{H}\right]-\mathrm{L}-\mathrm{MTX}$ and $20 \mu \mathrm{M}$ of D-MTX into rPCFT-HEK293 and Mock cells were measured at $\mathrm{pH}$ 6.0. The uptake times of L-MTX and D-MTX were 1 and 2 min, respectively. The uptake of $\left[{ }^{3} \mathrm{H}\right]-\mathrm{L}-\mathrm{MTX}$ was measured by liquid scintillation counting, whereas the uptake of D-MTX was measured by LC-MS/MS. It is noteworthy that there were no discernible differences in the uptake amounts of L-MTX measured by liquid scintillation counting and LC-MS/MS (data not shown). The uptake of $\left[{ }^{3} \mathrm{H}\right]$-L-MTX could therefore be reliably compared with that of D-MTX. The initial uptake rates of L- and D-MTX are shown in Fig. 6.

The rate of carrier-mediated uptake was calculated by subtracting the uptake into Mock cells from that into rPCFTexpressing cells, and the uptake clearance was then calculated by dividing the rate of carrier-mediated uptake by the initial concentration of the substrate (i.e., $0.2 \mu \mathrm{M}$ for L-MTX and $20 \mu \mathrm{M}$ for D-MTX). The rPCFT-mediated uptake clearances of L- and D-MTX were determined to be $124 \pm 5.6$ and
$3.27 \pm 0.43 \mu \mathrm{L} / \mathrm{min} / \mathrm{mg}$ protein (mean \pm S.D., $n=3$ ), respectively, which indicated that the uptake of L-MTX was approximately 40 -fold greater than that of D-MTX.

\section{DISCUSSION}

In our previous study, we demonstrated that the stereoselective absorption of L- and D-MTX occurred as a consequence of the stereoselective transport of the different enantiomers by human PCFT (hPCFT). ${ }^{17}$ In that study, hPCFT-expressing cells were used to show that L- and D-MTX are both substrates of the hPCFT and that the affinity of D-MTX $\left(K_{\mathrm{m}}: 211 \mu \mathrm{M}\right)$ for this transporter is about 40 -fold less than that of $\mathrm{L}-\mathrm{MTX}\left(K_{\mathrm{m}}\right.$ : $4.98 \mu \mathrm{M})$. The results of that study also revealed that the significant difference in the affinity of the MTX enantiomers for the hPCFT resulted in their stereoselective absorption. It was reported that there is a correlation between the polar surface area (PSA) and intestinal absorption, and that the drugs with PSA $>140 \AA^{2}$ are poorly absorbed only via passive diffusion. ${ }^{20)}$ Although MTX has a high PSA value (approximately $200 \AA^{2}$ ), the intestinal absorption of MTX is almost $100 \%$. These observations strongly support the idea that the absorption of MTX from the small intestine occurs mainly via transport by the PCFT.

In the current study, HEK293 cells stably expressing the rPCFT were established to confirm the species differences between rats and humans. In this experiment, the uptake of D-MTX had to be measured by LC-MS/MS analysis because isotope-labeled D-MTX was not available from a commercial supplier. Furthermore, since no difference was observed between the measurements obtained using liquid scintillation counting and LC-MS/MS methods, L-MTX was measured using a radioisotope.

Although the AIC value in two-component analysis of L-MTX was slightly smaller than that observed in singlecomponent analysis, the standard deviations of the parameters obtained in two-component analysis were much greater than those obtained in single-component analysis. Furthermore, the hPCFT-mediated uptake of L- and D-MTX showed a single 
A

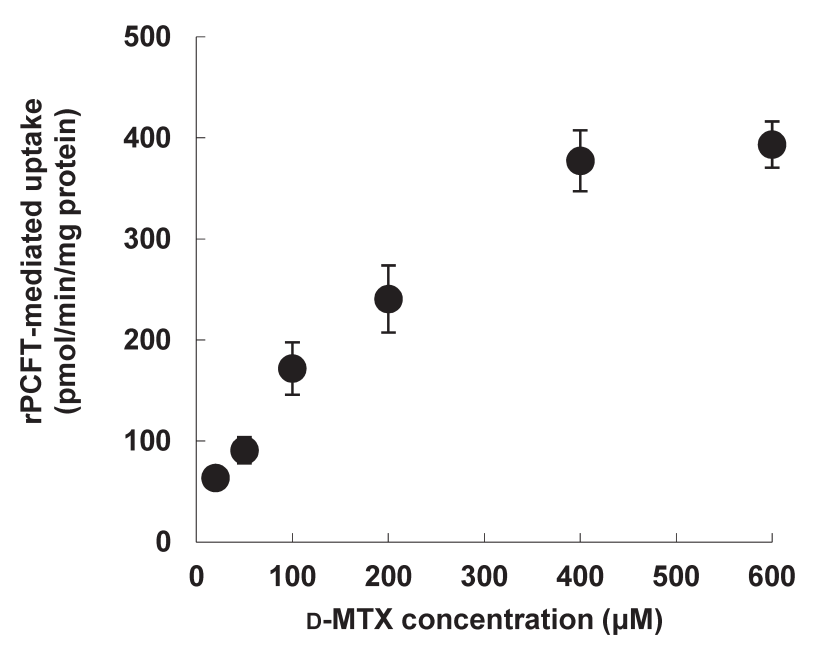

B

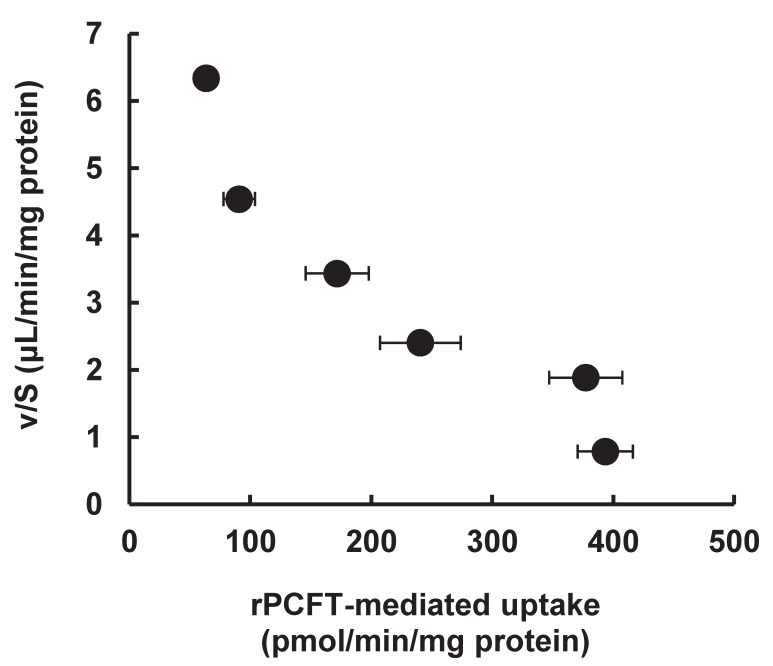

Fig. 5. Concentration Dependence of the Initial Rate of Uptake for rPCFT-Mediated D-MTX Uptake (A) Eadie-Hofstee Plot of rPCFT-Mediated Uptake of D-MTX (B)

Each point represents the mean \pm S.D. of three determinations. The rPCFT-mediated uptake was calculated by subtracting the uptake into Mock cells from that into rPCFT-HEK293 cells.

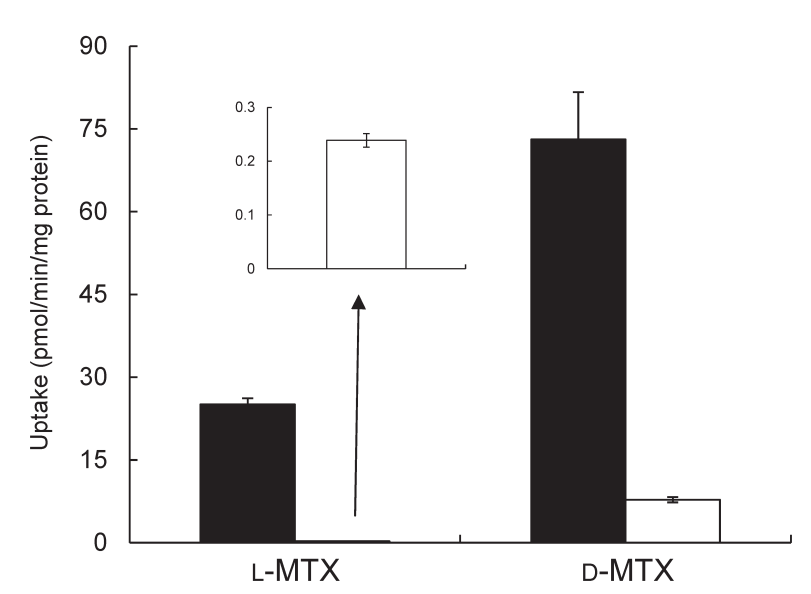

Fig. 6. Uptake Values of $0.2 \mu \mathrm{M}$ of L-MTX and $20 \mu \mathrm{M}$ of D-MTX

The uptake of L-MTX was measured for $1 \mathrm{~min}$ and that of D-MTX for $2 \mathrm{~min}$ in both cell types. Inset, magnified image of L-MTX uptake into Mock cells; rPCFT-transfected HEK293 cells; $\square$, vector-transfected HEK293 cells (Mock) Each column represents the mean \pm S.D. of three determinations.

component in our previous study, ${ }^{17)}$ and the uptake of D-MTX by the rPCFT in the current study was also a single component. The decision was therefore taken to use the $K_{\mathrm{m}}$ value obtained from single-component analysis to allow for the most effective comparison of the stereoselectivity of the rPCFT toward the transport of the different enantiomers of MTX.

The $K_{\mathrm{m}}$ value $(2.14 \mu \mathrm{M})$ determined for L-MTX in the current study was found to be similar to those reported previously in a range of different systems, including $0.6-2.6 \mu \mathrm{M}$ in HepG2 cells transfected with rPCFT cDNA, ${ }^{21)} 5.7 \mu \mathrm{M}$ in Xenopus oocytes injected with rPCFT cRNA, ${ }^{22)}$ and $1.0-4.6 \mu \mathrm{M}$ in HepG2 cells transfected with mouse PCFT cDNA. ${ }^{21}$

The Dixon plot showed that the uptake of L-MTX was inhibited in a competitive manner by unlabeled L-MTX, which gave a $K_{\mathrm{i}}$ value of $1.25 \mu \mathrm{M}$. It is noteworthy that this $K_{\mathrm{i}}$ value is almost equal to the $K_{\mathrm{m}}$ value $(2.14 \mu \mathrm{M})$ of L-MTX. D-MTX also inhibited the uptake of L-MTX in a competitive manner, with a $K_{\mathrm{i}}$ value of $149 \mu \mathrm{M}$. Taken together, these results clearly demonstrate that the affinity of D-MTX for the rPCFT is approximately 120 -fold less than that of L-MTX.

The $K_{\mathrm{m}}$ value $(192 \mu \mathrm{M})$ for the uptake of D-MTX was almost equal to its $K_{\mathrm{i}}$ value $(149 \mu \mathrm{M})$. Once again, a comparison of the $K_{\mathrm{m}}$ values between L-MTX $(2.14 \mu \mathrm{M})$ and D-MTX $(192 \mu \mathrm{M})$ revealed that the affinity of L-MTX for the PCFT was approximately 90 -fold greater than that of D-MTX.

The PCFT-mediated uptake clearance values of L-MTX and D-MTX were calculated as $V_{\max } / K_{\mathrm{m}}$, which gave values of 121 and $2.65 \mu \mathrm{L} / \mathrm{min} / \mathrm{mg}$ protein, respectively. The ratio of the rPCFT-mediated uptake clearance of L-MTX to that of D-MTX was therefore 46. In our previous study using hPCFTexpressing cells, ${ }^{17)}$ the PCFT-mediated uptake clearance values of L-MTX and D-MTX were 179 and $4.31 \mu \mathrm{L} / \mathrm{min} / \mathrm{mg}$ protein, respectively, and the ratio of the hPCFT-mediated uptake clearance of L-MTX to that of D-MTX was 42. These results therefore demonstrated that there was very little difference between the uptake clearance ratios of the MTX enantiomers in the rPCFT and hPCFT.

Qiu et $a l .{ }^{21)}$ also reported the results of their study on the stereoselectivity of PCFTs from rats and mice. In their study, both rat and mouse PCFTs showed a significant difference in the inhibitory activities between (6S)- and (6R)-5-formyltetrahydrofolate against the uptake of FA. Qiu et al. ${ }^{21)}$ also estimated that there was an approximate six-fold difference in the affinity of the enantiomers for both rPCFT and mouse PCFT, and their observations showed similar stereoselectivity between the two PCFTs. In a separate study, Menter et al. ${ }^{23}$ ) reported that the hPCFT-mediated uptake of the different enantiomers of aminopterin (AMT) occurred in a stereoselective manner, and that the $V_{\max } / K_{\mathrm{m}}$ value of L-AMT was approximately 35 -fold greater than that of D-AMT.

Species differences have been reported for several other transporters. For example, the transport of kynurenic acid by organic anion transporter 1 (OAT1, SLC22A6) and OAT3 (SLC22A8) was examined, and no differences were observed in the affinity of kynurenic acid for OAT1 and OAT3 between humans and rats. ${ }^{24,25)}$ The $K_{\mathrm{m}}$ values for the interac- 
tion of kynurenic acid with human and rat OAT1 were 5.06 and $8.46 \mu \mathrm{M}$, respectively. The $K_{\mathrm{m}}$ values for the interaction of kynurenic acid with human and rat OAT3 were almost identical (approximately $4.8 \mu \mathrm{M}$ ). The $\mathrm{Na}^{+}$-dependent taurocholate cotransporting polypeptide (NTCP, SLC10A1), which is a major transporter of bile acids in hepatocytes, showed species differences in terms of its inhibition by bosentan. ${ }^{26}$ Taurocholate uptake was inhibited in a competitive manner by bosentan in the human NTCP with a $K_{\mathrm{i}}$ value of $18 \mu \mathrm{M}$, whereas the uptake of taurocholate was inhibited in a noncompetitive manner by bosentan in the rat NTCP. Multidrug resistance-associated protein $2(\mathrm{MRP} 2, \mathrm{ABCC} 2)$ transports a variety of different drug molecules and metabolites, including glutathione, glucuronide, and sulfate conjugates, across extraand intracellular membranes. Takekuma et al. $^{27)}$ investigated the inhibitory effects of the mycophenolic acid glucuronide (MPAG) metabolite on the transport of $p$-aminohippuric acid and found that MPAG gave $\mathrm{IC}_{50}$ values of 286 and $1036 \mu \mathrm{M}$ for rat and human MRP2, respectively. The results demonstrated that the affinity of MPAG to rat MRP2 is 3.6-fold greater than that to human MRP2.

The results of the current study showed that the rPCFTmediated transport of the different enantiomers of MTX occurs with a high degree of stereoselectivity. Furthermore, the stereoselectivity of the rPCFT was found to be comparable to that of the hPCFT. We showed that there are no species differences in substrate recognition of PCFT between humans and rats. The present observations indicate that rats may be a good model to predict carrier-mediated intestinal absorption of folates and their analogues in humans.

According to our observations, species differences are seen in the stereoselectivity of the RFC between humans and rats. The hRFC exhibited a high level of stereoselectivity toward the different enantiomers of MTX, whereas the rRFC showed almost no stereoselectivity. The hPCFT and rPCFT proteins share $87 \%$ amino acid identity, and the hRFC and rRFC proteins share only $64 \%$ amino acid identity. Since PCFT proteins are highly conserved between humans and rats, this may result in the similar structure of the substrate recognition site and similar stereoselectivity.

Conflict of Interest The authors declare no conflict of interest.

\section{REFERENCES}

1) Sirotnak FM, Tolner B. Carrier-mediated membrane transport of folates in mammalian cells. Annu. Rev. Nutr., 19, 91-122 (1999).

2) Matherly LH, Goldman ID. Membrane transport of folates. Vitam. Horm., 66, 403-456 (2003).

3) Qiu A, Jansen M, Sakaris A, Min SH, Chattopadhyay S, Tsai E, Sandoval C, Zhao R, Akabas MH, Goldman ID. Identification of an intestinal folate transporter and the molecular basis for hereditary folate malabsorption. Cell, 127, 917-928 (2006).

4) Zhao R, Matherly LH, Goldman ID. Membrane transporters and folate homeostasis: intestinal absorption and transport into systemic compartments and tissues. Expert Rev. Mol. Med., 11, e4 (2009).

5) Nguyen TT, Dyer DL, Dunning DD, Rubin SA, Grant KE, Said HM. Human intestinal folate transport: cloning, expression, and distribution of complementary RNA. Gastroenterology, 112, 783-791 (1997).

6) Dixon KH, Lanpher BC, Chiu J, Kelley K, Cowan KH. A novel
cDNA restores reduced folate carrier activity and methotrexate sensitivity to transport deficient cells. J. Biol. Chem., 269, 17-20 (1994).

7) Moscow JA, Gong M, He R, Sgagias MK, Dixon KH, Anzick SL, Meltzer PS, Cowan KH. Isolation of a gene encoding a human reduced folate carrier (RFC1) and analysis of its expression in transport-deficient, methotrexate-resistant human breast cancer cells. Cancer Res., 55, 3790-3794 (1995).

8) Prasad PD, Ramamoorthy S, Leibach FH, Ganapathy V. Molecular cloning of the human placental folate transporter. Biochem. Biophys. Res. Commun., 206, 681-687 (1995).

9) Williams FMR, Murray RC, Underhill TM, Flintoff WF. Isolation of a hamster cDNA clone coding for a function involved in methotrexate uptake. J. Biol. Chem., 269, 5810-5816 (1994).

10) Williams FMR, Flintoff WF. Isolation of human cDNA that complements a mutant hamster cell defective in methotrexate uptake. $J$. Biol. Chem., 270, 2987-2992 (1995).

11) Wong SC, Proefke SA, Bhushan A, Matherly LH. Isolation of human cDNAs that restore methotrexate sensitivity and reduced folate carrier activity in methotrexate transport-defective Chinese hamster ovary cells. J. Biol. Chem., 270, 17468-17475 (1995).

12) Wang Y, Zhao R, Goldman ID. Characterization of a folate transporter in HeLa cells with a low $\mathrm{pH}$ optimum and high affinity for pemetrexed distinct from the reduced folate carrier. Clin. Cancer Res., 10, 6256-6264 (2004).

13) Geller J, Kronn D, Jayabose S, Sandoval C. Hereditary folate malabsorption: family report and review of the literature. Medicine, $\mathbf{8 1}$, 51-68 (2002).

14) Zhao R, Min SH, Qiu A, Sakaris A, Goldberg GL, Sandoval C, Malatack JJ, Rosenblatt DS, Goldman ID. The spectrum of mutations in the PCFT gene, coding for an intestinal folate transporter, that are the basis for hereditary folate malabsorption. Blood, 110, $1147-1152$ (2007)

15) Lasry I, Berman B, Straussberg R, Sofer Y, Bessler H, Sharkia M, Glaser F, Jansen G, Drori S, Assaraf YG. A novel loss of function mutation in the proton-coupled folate transporter from a patient with hereditary folate malabsorption reveals that Arg 113 is crucial for function. Blood, 112, 2055-2061 (2008).

16) Hendel J, Brodthagen H. Entero-hepatic cycling of methotrexate estimated by use of the D-isomer as a reference marker. Eur. J. Clin. Pharmacol., 26, 103-107 (1984).

17) Narawa $T$, Itoh $T$. Stereoselective transport of amethopterin enantiomers by the proton-coupled folate transporter. Drug Metab. Pharmacokinet., 25, 283-289 (2010).

18) Narawa $T$, Yanagisawa $H$, Itoh $T$. Stereoselective transport of human His27- and Arg27-reduced folate carrier. Biol. Pharm. Bull., 37, 439-446 (2014).

19) Yamaoka $K$, Tanigawara $Y$, Nakagawa $T$, Uno T. A pharmacokinetic analysis program (MULTI) for microcomputer. J. Pharmacobiodyn., 4, 879-885 (1981).

20) Clark DE. Rapid calculation of polar molecular surface area and its application to the prediction of transport phenomena. 1. Prediction of intestinal absorption. J. Pharm. Sci., 88, 807-814 (1999).

21) Qiu A, Min SH, Jansen M, Malhotra U, Tsai E, Cabelof DC, Matherly LH, Zhao R, Akabas MH, Goldman ID. Rodent intestinal folate transporters (SLC46A1): Secondary structure, functional properties, and response to dietary folate restriction. Am. J. Physiol. Cell Physiol., 293, C1669-C1678 (2007).

22) Inoue $K$, Nakai $Y$, Ueda $S$, Kamigaso $S$, Ohta $K$, Hatakeyama M, Hayashi Y, Otagiri M, Yuasa H. Functional characterization of PCFT/HCP1 as the molecular entity of the carrier-mediated intestinal folate transport system in the rat model. Am. J. Physiol. Gastrointest. Liver Physiol., 294, G660-G668 (2008).

23) Menter A, Thrash B, Cherian C, Matherly LH, Wang L, Gangjee A, Morgan JR, Maeda DY, Schuler AD, Kahn SJ, Zebala JA. Intestinal transport of aminopterin enantiomers in dogs and humans with 
psoriasis is stereoselective: evidence for a mechanism involving the proton-coupled folate transporter. J. Pharmacol. Exp. Ther., 342, 696-708 (2012).

24) Uwai $\mathrm{Y}$, Honjo $\mathrm{H}$, Iwamoto $\mathrm{K}$. Interaction and transport of kynurenic acid via human organic anion transporters hOAT1 and hOAT3. Pharmacol. Res., 65, 254-260 (2012).

25) Uwai Y, Hara H, Iwamoto K. Transport of kynurenic acid by rat organic anion transporters rOAT1 and rOAT3: Species difference between human and rat in OAT1. Int. J. Tryptophan Res., 6, 1-6 (2013).
26) Leslie EM, Watkins PB, Kim RB, Brouwer KLR. Differential inhibition of rat and human $\mathrm{Na}^{+}$-dependent taurocholate cotransporting polypeptide (NTCP/SLC10A1) by bosentan: A mechanism for species differences in hepatotoxicity. J. Pharmacol. Exp. Ther., 321, 1170-1178 (2007)

27) Takekuma Y, Kakiuchi H, Yamazaki K, Miyauchi S, Kikukawa T, Kamo N, Ganapathy V, Sugawara M. Difference between pharmacokinetics of mycophenolic acid (MPA) in rats and that in humans is caused by different affinities of MRP2 to a glucuronized form. $J$. Pharm. Pharm. Sci., 10, 71-85 (2007). 